\title{
Review Article \\ Effects of Withania somnifera on Reproductive System: A Systematic Review of the Available Evidence
}

\author{
Ramin Nasimi Doost Azgomi $\left(\mathbb{D},{ }^{1}\right.$ Afshar Zomorrodi ${ }^{\mathbb{D}},{ }^{2}$ Hossein Nazemyieh, \\ Seyed Mohammad Bagher Fazljou, ${ }^{1}$ Homayoun Sadeghi Bazargani $\left({ }^{1},{ }^{4,5}\right.$ \\ Fatemeh Nejatbakhsh, ${ }^{6}$ Arezoo Moini Jazani, ${ }^{1}$ and Yadollah Ahmadi AsrBadr ${ }^{7}$ \\ ${ }^{1}$ Department of Iranian Traditional Medicine, School of Traditional Medicine, Tabriz University of Medical Sciences, Tabriz, Iran
${ }^{2}$ Department of Urology, Emam Reza Hospital, Tabriz University of Medical Sciences, Tabriz, Iran
${ }^{3}$ Research Center for Pharmaceutical Nanotechnology, Faculty of Pharmacy, Tabriz University of Medical Sciences, Tabriz, Iran
${ }^{4}$ Road Traffic Injury Research Center, Tabriz University of Medical Sciences, Tabriz, Iran
${ }^{5}$ Department of Statistics and Epidemiology, Faculty of Health, Tabriz University of Medical Sciences, Tabriz, Iran
${ }^{6}$ Department of Iranian Traditional Medicine, School of Traditional Medicine, Tehran University of Medical Sciences, Tehran, Iran
${ }^{7}$ Department of Urology, Sina Hospital, Tabriz University of Medical Science, Tabriz, Iran
}

Correspondence should be addressed to Afshar Zomorrodi; Dr_zomorrodi@yahoo.com

Received 23 September 2017; Accepted 7 December 2017; Published 24 January 2018

Academic Editor: Leon Spicer

Copyright (c) 2018 Ramin Nasimi Doost Azgomi et al. This is an open access article distributed under the Creative Commons Attribution License, which permits unrestricted use, distribution, and reproduction in any medium, provided the original work is properly cited.

\begin{abstract}
Introduction. Withania somnifera (WS) also known as ashwagandha is a well-known medicinal plant used in traditional medicine in many countries for infertility treatment. The present study was aimed at systemically reviewing therapeutic effects of WS on the reproductive system. Methods. This systematic review study was designed in 2016. Required data were obtained from PubMed, Scopus, Google Scholar, Cochrane Library, Science Direct, Web of Knowledge, Web of Science, and manual search of articles, grey literature, reference checking, and expert contact. Results. WS was found to improve reproductive system function by many ways. WS extract decreased infertility among male subjects, due to the enhancement in semen quality which is proposed due to the enhanced enzymatic activity in seminal plasma and decreasing oxidative stress. Also, WS extract improved luteinizing hormone and follicular stimulating hormone balance leading to folliculogenesis and increased gonadal weight, although some animal studies had concluded that WS had reversible spermicidal and infertilizing effects in male subjects. Conclusion. WS was found to enhance spermatogenesis and sperm related indices in male and sexual behaviors in female. But, according to some available evidences for spermicidal features, further studies should focus on the extract preparation method and also dosage used in their study protocols.
\end{abstract}

\section{Introduction}

Infertility is a complicated problem with physiologic, psychologic, and economic aspects. Infertility is defined as the inability to conceive after one year of unprotected sexual intercourse [1]. About 15 percent of couples worldwide suffer infertility [2]. One in six couples is involved with infertility during their reproductive age. Based on World Health Organization report, 60-80 million couples suffer from failure of fertility worldwide [3]. It may be difficult to diagnose the reason for infertility but it may include either dysregulation of sex hormonal axis in both men and women or anatomical anomalies [4]. According to different studies, approximately $20 \%-50 \%$ of infertility is due to male, $40 \%$ is due to female factors, and $25 \%$ of causes are unknown $[1,5]$.

The causes of male infertility are classified as pretesticular, testicular, posttesticular, and unknown. Sperm abnormality causes $30 \%-40 \%$ of all infertility [6]. Pretesticular causes include disorders in the hypothalamus-pituitary-gonadal axis, systemic diseases, sexual dysfunction, and psychopathy. Testicular dysfunction due to multiple reasons as infection, trauma, varicocele, cryptorchidism, chromosomal anomalies, alcohol, cigarettes, drugs, and radiation is another cause of male infertility. Posttesticular disorders comprise the 
abnormalities in sperm transfer such as obstruction or dysfunction of epididymis and ductus deferens, immunological defects, and anatomical abnormalities like hypospadias [7, 8].

Different etiologies of female infertility include ovarian diseases, tubal disorders, endometriosis, uterine pathologies, cervical problems, congenital anomalies, and dysfunction of the hypothalamus-pituitary-ovarian axis and systemic diseases $[1,9]$. Treatment of infertility may vary due to the different etiologies but it ranges from simple pharmacological treatments to advanced laboratory procedures and surgeries. In developing countries, due to the lack of adequate equipment to diagnosis and treatment for many infertility causes and also probable long-term diagnosis process, many people tend to use alternative and complementary medicine [10]. Herbal medicines are one of the main modalities used in this field.

Withania somnifera, (WS) also known as ashwagandha, Indian ginseng, winter cherry, horse smell, Kaknaje Hindi, is a well-known medicinal plant in Solanaceae family used in traditional medicine in many countries such as Iran and India [11]. This plant is known to cure impotency and increase sex appeal and fertility when used solitarily or in combination with other medications $[12,13]$. This wild plant grows in dry and hot-semiarid climate such as southern Mediterranean region, Canary Islands, and northern Africa to northern India (Iran, Jordan, Sudan, Palestine, Afghanistan, and Egypt) $[14,15]$. Different parts of this plant such as roots, leaves, flowers, seeds, stems, and fruits are used as remedy in traditional medicine of different countries [16-18]. Many phytochemicals have been extracted so far from this plant with possessing different pharmacologic and biological properties [19].

WS has been recommended for management of polyarthritis, lumbago, painful swellings, premature ejaculation, oligospermia, plague, asthma, vitiligo, general debility, impotency, ulcers, uterine infection, leucorrhoea, hemorrhoid, and orchitis in traditional Persian medicine $[60,61]$. All these therapeutic uses suggest its anti-inflammatory, aphrodisiac, semenogogue, and deobstruent features [62-65]. As far as there are no wide-spectrum and specific studies or systematic reviews about therapeutic effects of WS, on male and female reproductive system, the present study was trying to systemically review therapeutic effects of WS on reproductive system and fertility disorders.

\section{Methods}

2.1. Study Design and Search Strategy. In this systematic review which was performed in 2016, required data were gathered using databases such as Google Scholar, PubMed, Scopus, Web of Science, and Cochrane Library. The keywords used in present study were "Withania somnifera" (also equivalent terms), "fertility", "conceive", "infertility", “women", "men”, "female", "male”, "semen", "sperm”, "spermicidal”, "Sertoli”, “prolactin”, "follicular stimulating hormone", "luteinizing hormone", "testosterone", "libido", "aphrodisiac", "behavior", "sexual”, "spermatogenesis", "reproduction", “semenogogue”, “impotency”, "spermatozoa", "estrogen”, "pregnancy”, "gonadotropin releasing hormone", "testis", "leydig", and "ovarian". The time period between 1965 and 2017 was selected. Also, to increase the scope of the study, manual search in some of the valid journal databases was performed. All in vitro or in vivo studies about the effects of WS on reproductive system and fertility among human or animal subjects were included in the study. Review studies, case reports, letter to editors, and short communications were excluded from the study.

To search for unpublished articles (grey literature), European Association for Grey Literature Exploitation (EAGLE) and Health Care Management Information Consortium (HMIC) were searched.

2.2. Articles Evaluation. The selected papers extracted from the databases were assessed by two investigators using Consort 2010 checklist. Discrepancies between the two raters were referred to the third investigator. First, the titles of all articles were reviewed to screen for eligibility and those found to be irrelevant with the objectives of the study were excluded from the study. In the later stages, the abstracts and full-text articles were, respectively, examined to identify and exclude those that did not match the inclusion.

2.3. Data Extraction. One reviewer extracted the data from the included studies while a second author checked the results. Any disagreements were resolved by a discussion of reviewers. Data for the primary objective of the review was collected from the full text of each publication and included the trial name, year of publication, type of study, sample size, results, and other characteristics.

2.4. Statistical Analysis. Statistical analysis was performed by SPSS software package version 16.0 for windows (SPSS Inc., Chicago, USA) [66]. Quantitative data are presented as mean \pm standard deviation (SD), while qualitative data are demonstrated as frequency and percent (\%).

\section{Results}

The flowchart of the study is shown in Figure 1. Of 459 recognized studies, 42 studies were included in the present study. These studies were composed of 8 human studies (7 studies on men and one among women), 28 animal studies (20 studies of male animals and 8 studies on female animals), 5 animal-cellular studies, and one cellular study. In these studies, roots (29 studies), leaves (7 studies), fruits (2 studies), unknown extract (2 studies), and stems (1 study) were used. Characteristics and results of human, animal, and animalcellular studies are shown in Tables 1,2 , and 3, respectively. In all human studies, root extract was used. The duration of human studies ranged from 60 to 90 days. Mostly the WS extract was used orally and once daily in 50 percent of human studies. In the most studies, no side effects were found for WS extract during of studies [17, 20, 21, 30, 36, 40, 45, 46, 58].

Many phytochemicals have been extracted from WS, which includes alkaloids, flavonoids, steroidal lactones, saponins, neurotransmitters, essential and nonessential fatty acids, ergostane, and gamma amino butyric acid; of all these components, alkaloids, and withanolids such as withaferin 


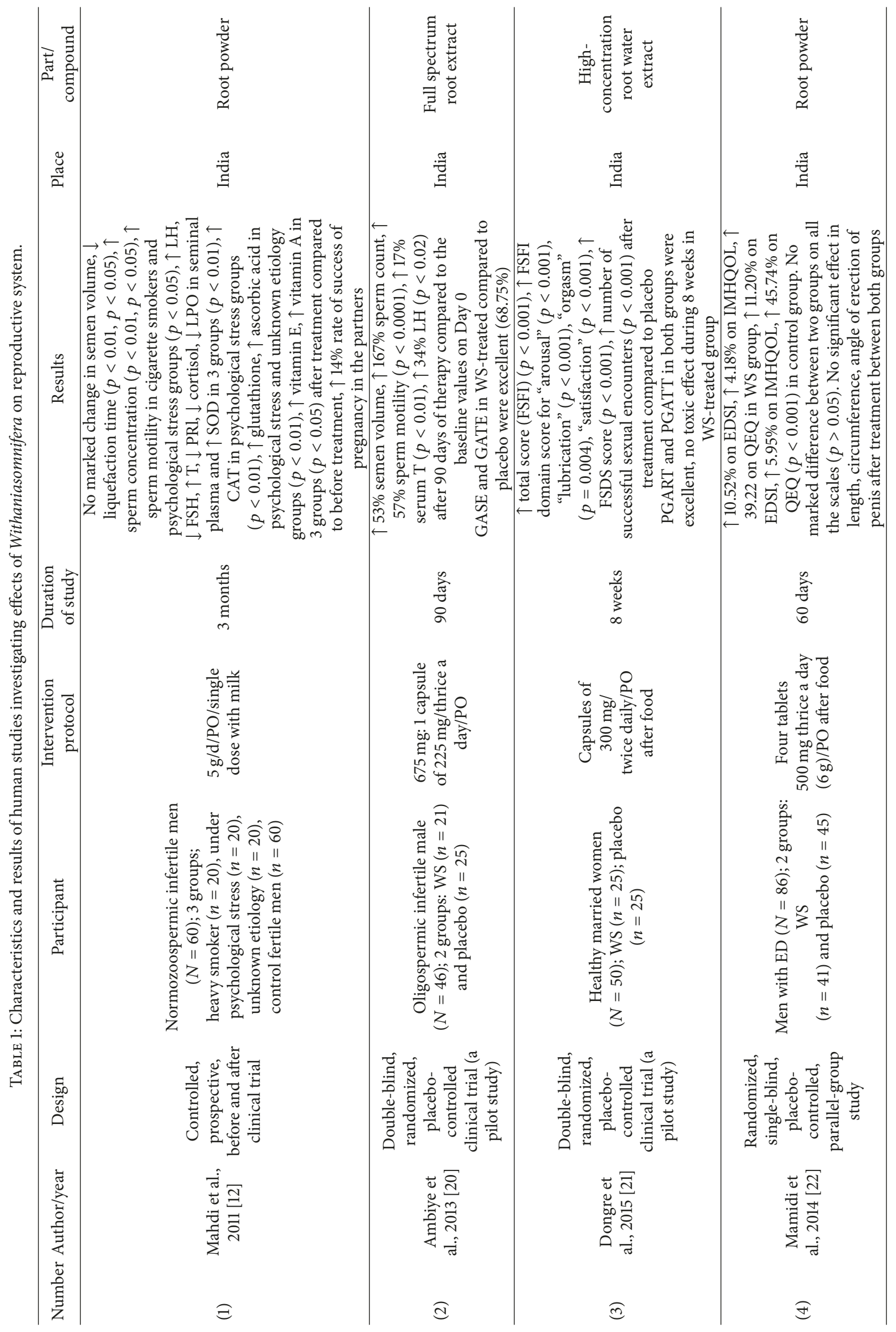




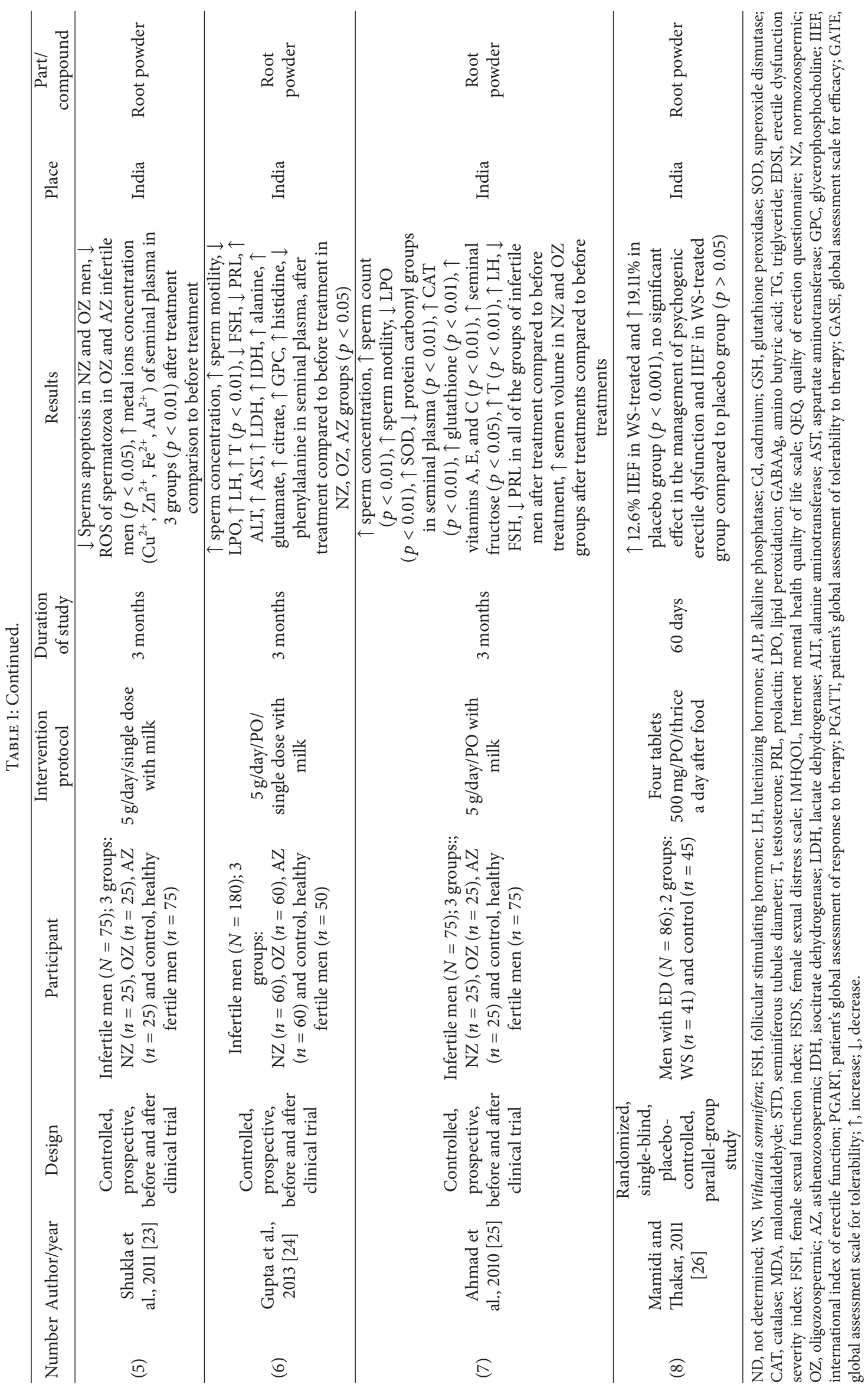




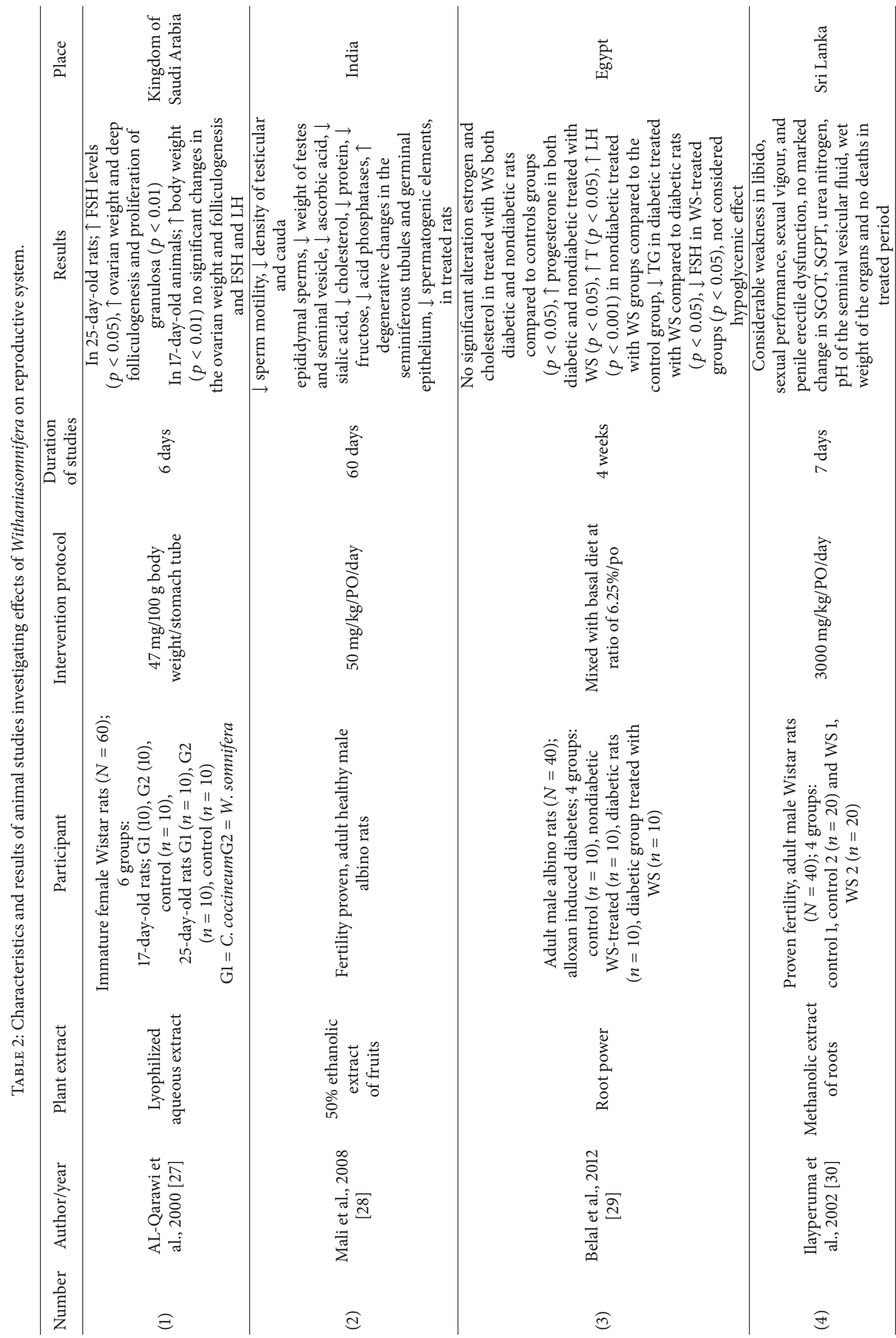




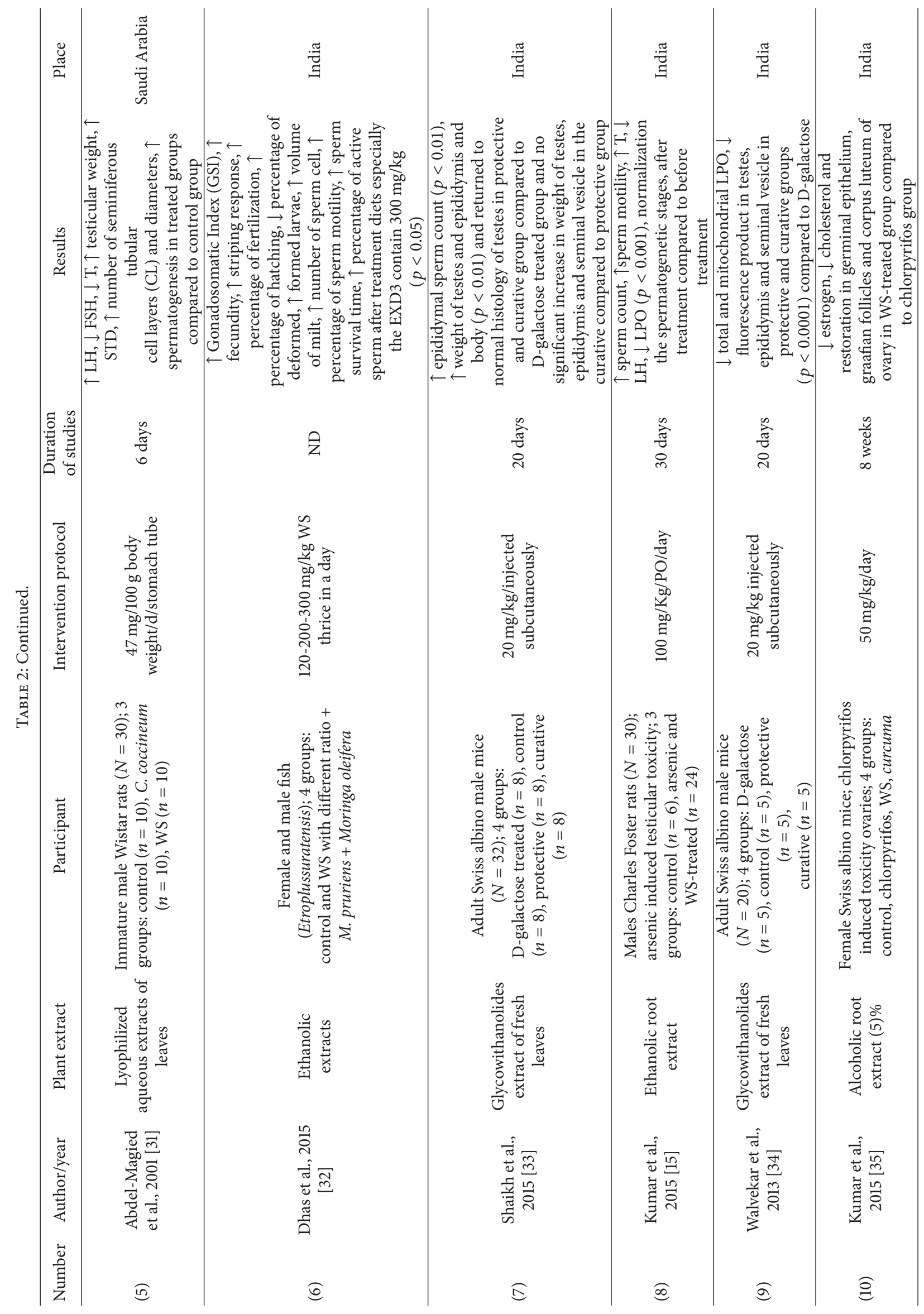




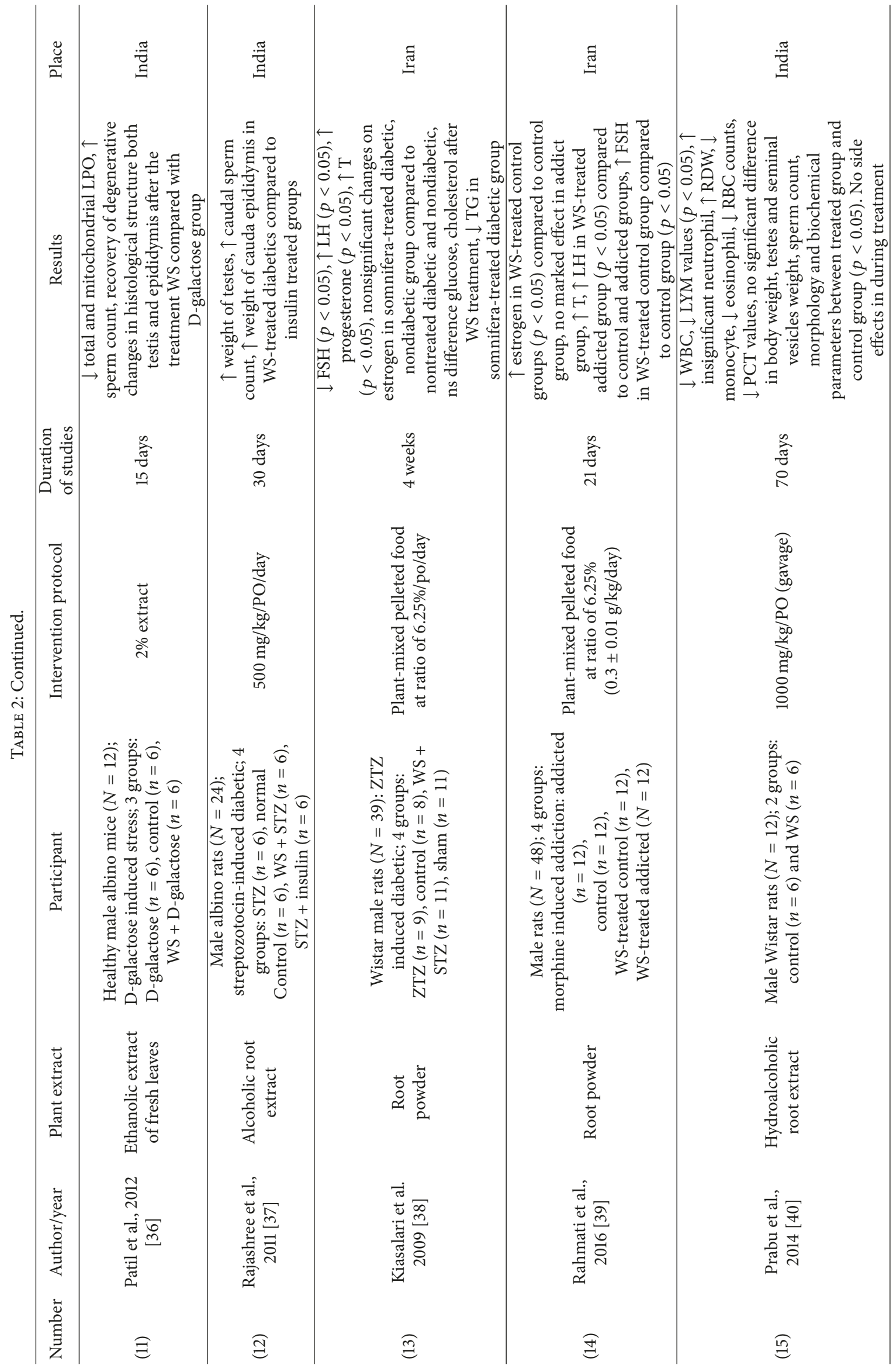




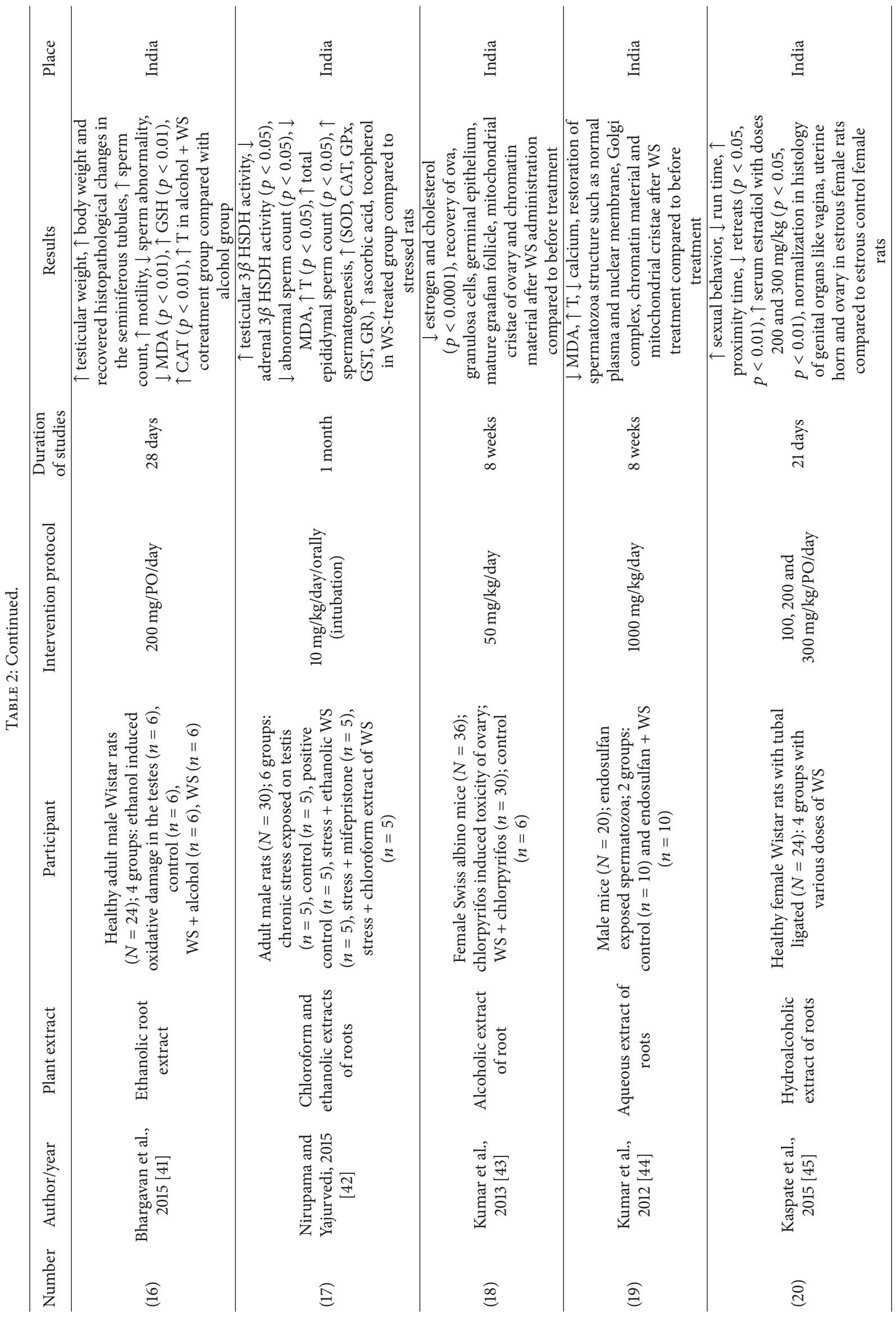




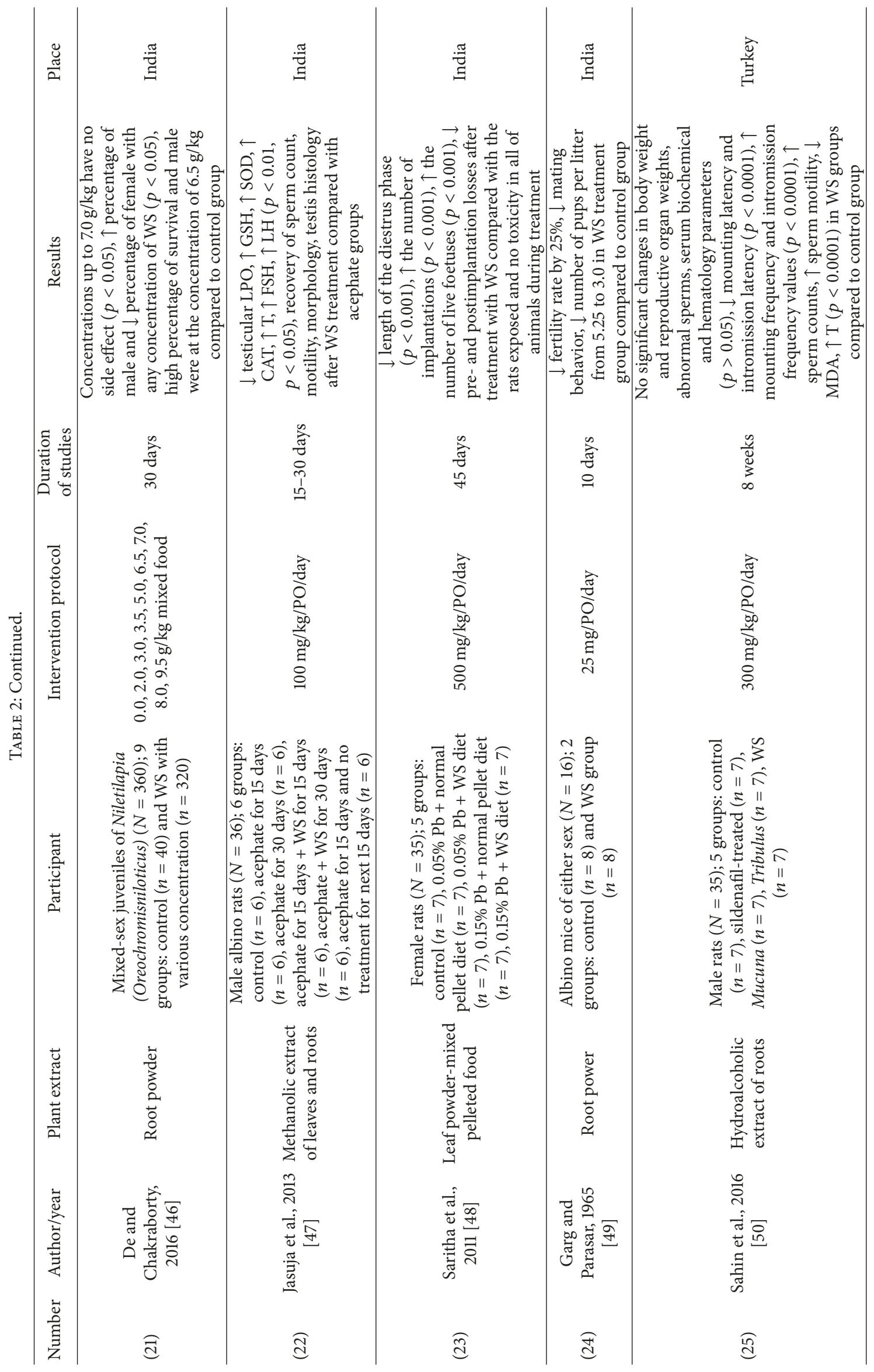




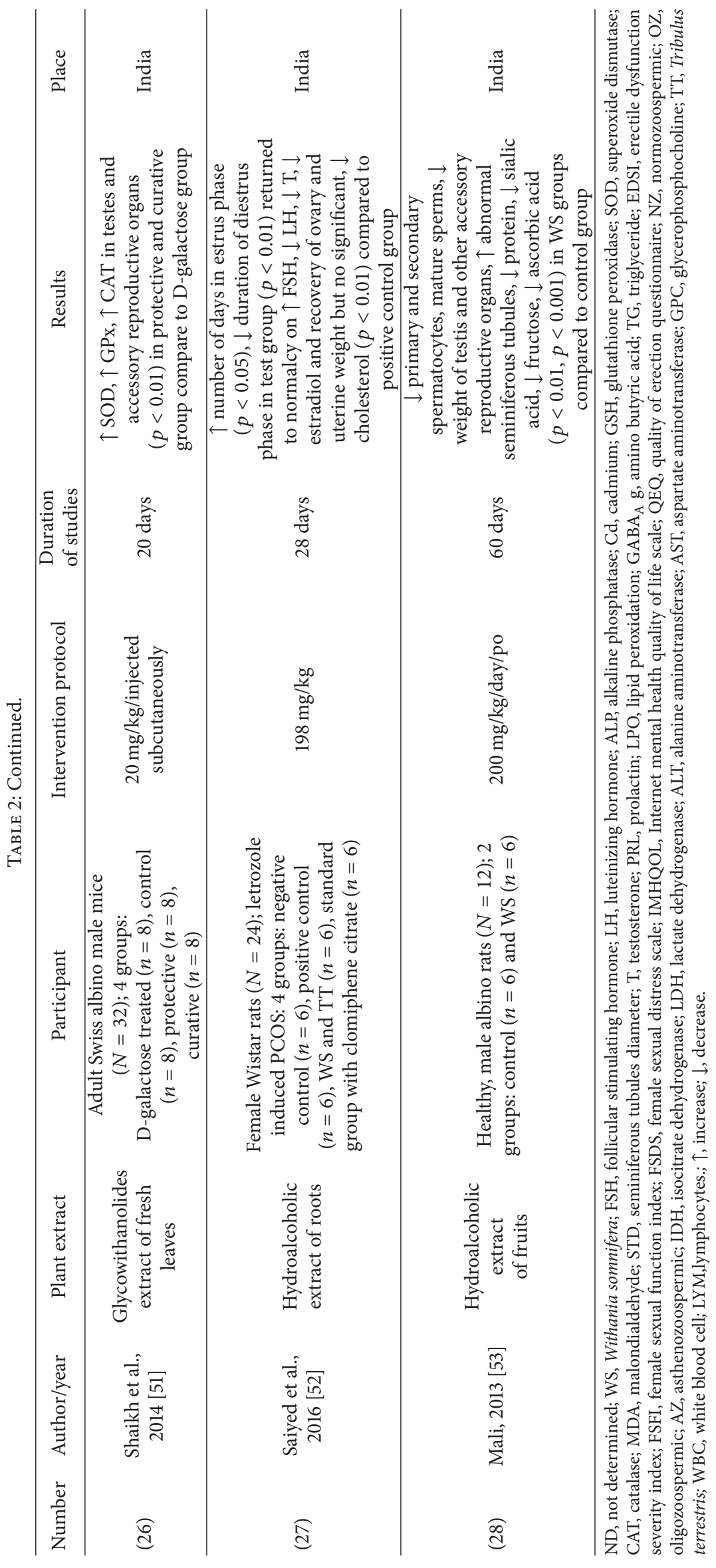




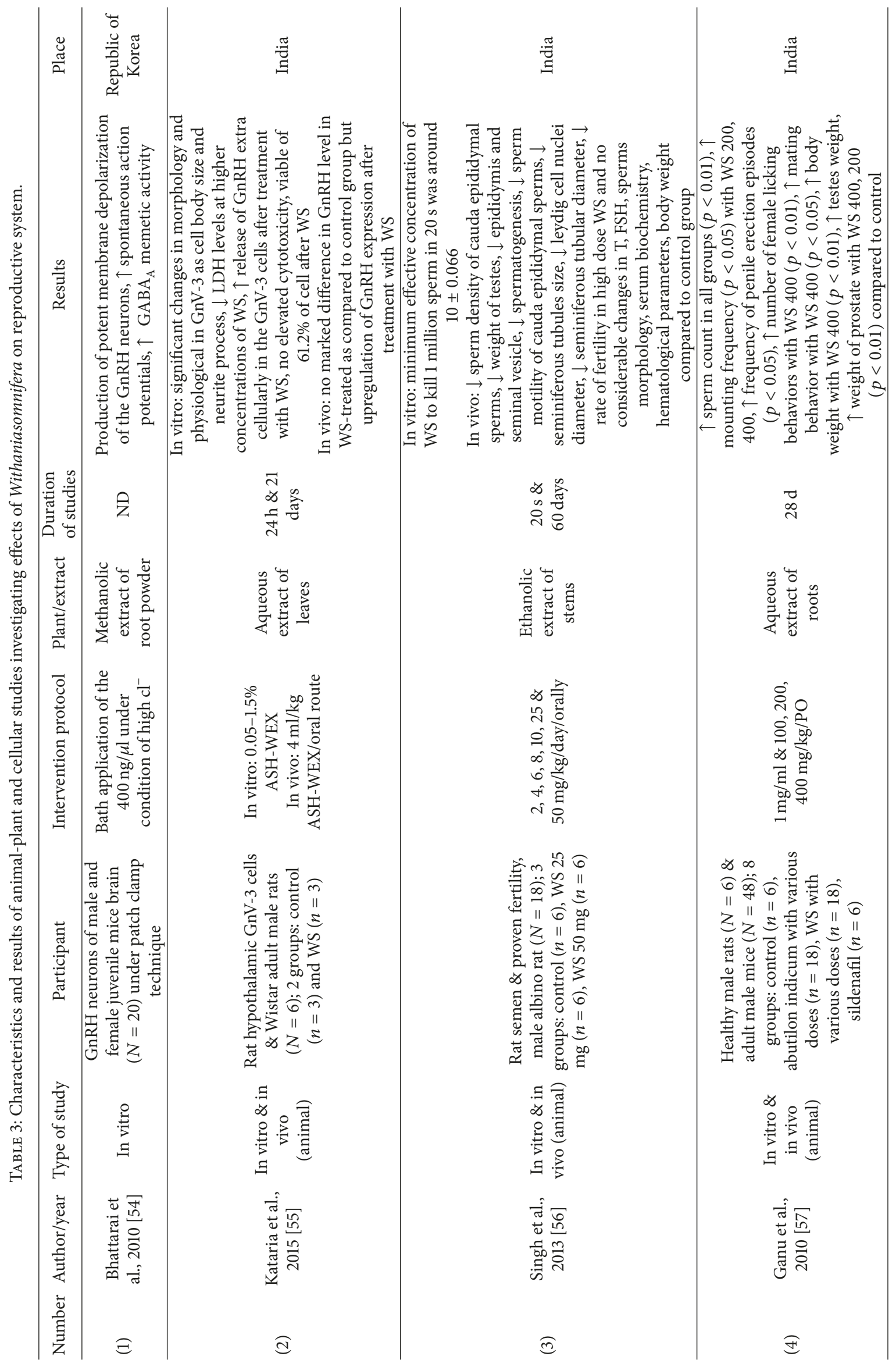




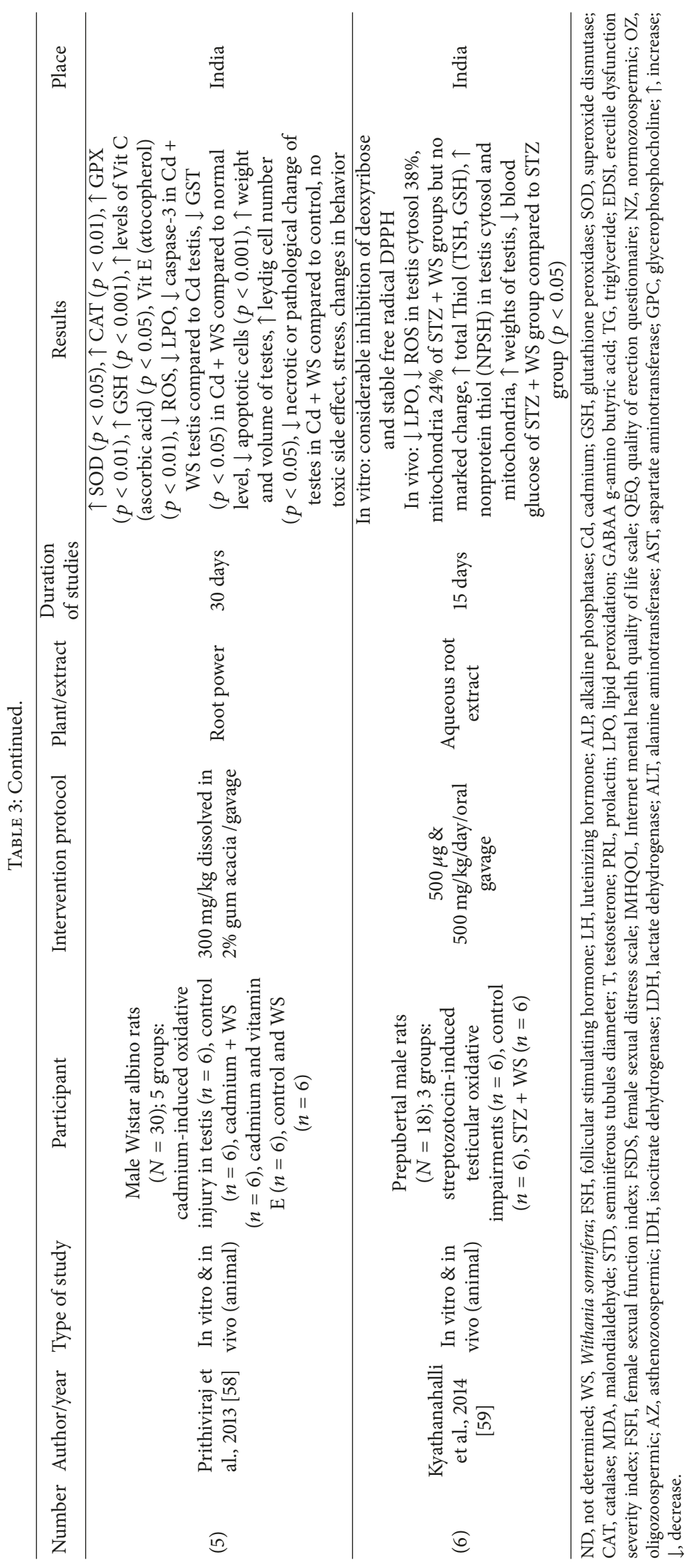



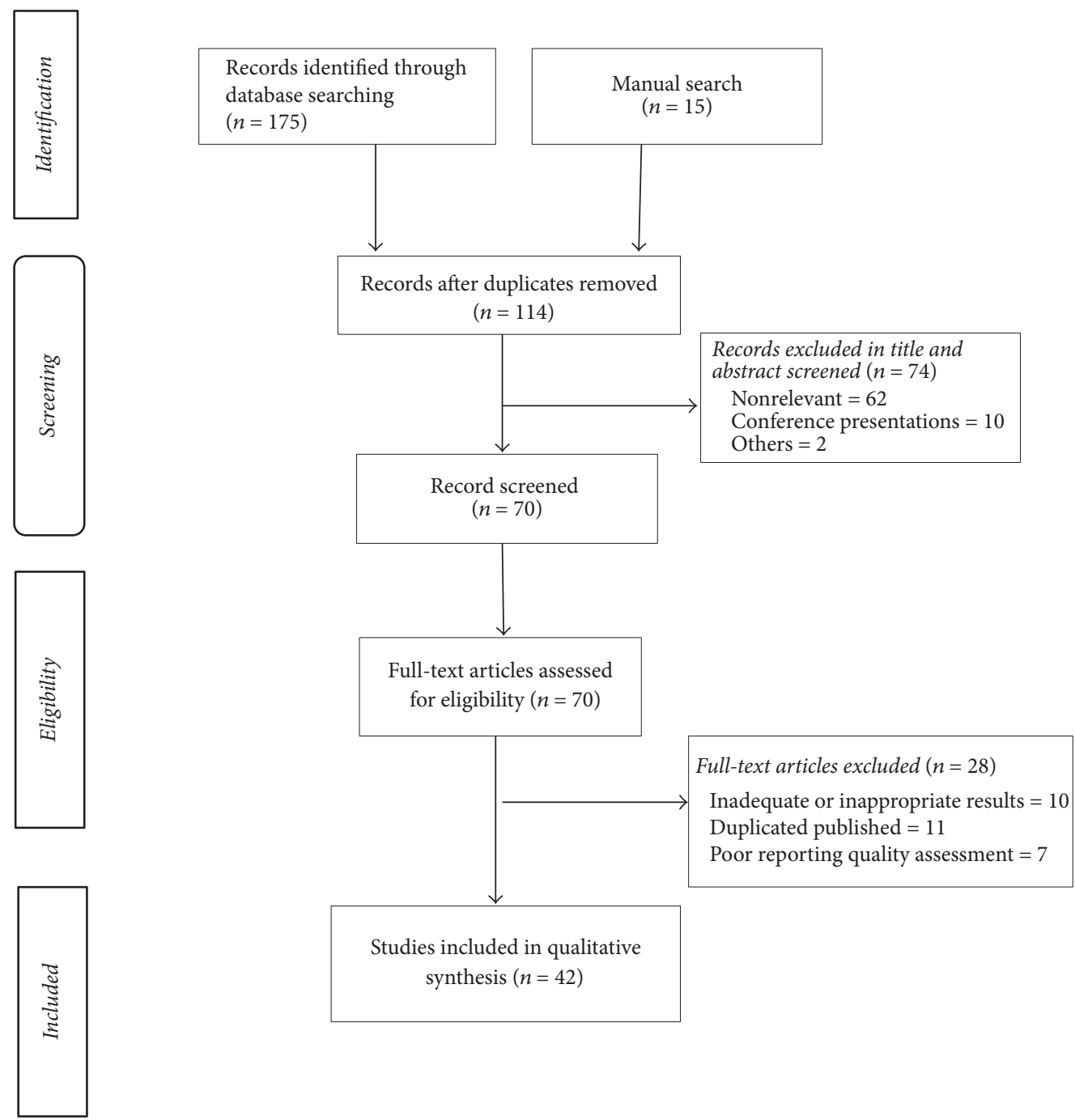

FIGURE 1: Flowchart of the systematic review process searching for studies investigating Withania somnifera on reproductive system.

A, withanosides, sitoindosides, beta-sitosterol, and various amino acids like alanine have more prominent effect on fertility status [20, 23-25, 28-30, 34, 38, 51, 55].

In animal studies, WS is known to have gonadotropic function which increases gonadal weight by growthing follicles size in female and also increasing seminiferous tubular cell layers in male animals [27, 28, 31, 33, 35, 37, 41, 57-59]. WS is found to improve spermatogenic activity which is proposed to be due to supporting hypothalamic-hypophysial-gonadal hormonal axis and testosterone balance in testes [15, 31, 42]. WS is found to compensate $\mathrm{LH}$ and FSH decrease or increase in diabetic Wistar rats [27, 29, 31, 38, 47]. Also, WS increases testosterone $[15,29,38,39,44,47]$ and progesterone $[29,38]$ in male rats and decreases triglyceride and cholesterol in both male and female rats $[28,29,35,38,43,52]$.

In a study by Shukla et al. about effects of WS on men, WS root powder was used for 3 months and it was shown that sperm parameters such as count and motility in sperm analysis had improved due to decrease apoptosis and reactive oxidative stress among men with normospermia and oligospermia; also copper, zinc, iron, and gold ions of seminal plasma had increased after the treatment and subsequently semen quality increased. This increase in semen quality is proposed to be due to the increase in essential neurotransmitters, metallothionein which has antioxidative function, and metal ions as cofactors for essential enzymes [23].

In two clinical trials, the effects of 5 grams of WS root for 3 months on semen parameters of infertile men were investigated. Improvement in semen quality, increased vitamins $\mathrm{E}, \mathrm{C}$, and $\mathrm{A}$, and increased fertility were reported which is proposed to be due to the high amount of alkaloids, ergostane steroids, and essential amino acids in WS which improved detoxification, decreased oxidative stress, and restorated testosterone secretion $[12,25]$.

In another human study, treatment by WS aqueous extract in married healthy women increased their sexual function index and diminished sexual distress index 
statistically significant [21]. In two studies using WS root extract for men with psychologic erectile dysfunction, there was no statistically significant difference between the intervention and control group considering sexual function indices $[22,26]$. Also, WS root extract was found to decrease prolactin level after 3 months of administration among infertile men [12, 24, 25].

In a study by Bhattarai et al. about effects of WS root extract, it was found that GABA mimetic features of this extract led to an increased activity of gonadotropin releasing hormone secreting neurons [54]. On the other hand, WS root extract was found to decrease libido and sexual function which led to impotency and erectile dysfunction in animal studies [30]. Ethanolic WS fruit and stem extract were found to induce infertility in male rats due to the decrease in sperm motility, count, and degeneration of seminiferous tubules, although this extract did not have an effect on sperm morphology $[28,53,56]$.

Prabu et al. in a study on male rats found that hydroalcoholic WS root extract was found to decrease white blood cell and lymphocyte counts in blood, but no considerable effect on reproductive indices [40]. Alcoholic WS root extract can decrease estrogen and cholesterol level in female Wistar mice and recover corpus luteum, graafian follicles, and germinal epithelium which has been damaged due to the chlorpyrifos exposure [35].

WS leaves and roots have been found to improve oxidative stress indices such as an increase in superoxide dismutase, catalase, glutathione, lactate dehydrogenase, alanine, glutamine, phenylalanine, and decrease in cortisol and fructose $[12,22-25,34,36,47,51,58]$.

In a study investigating effects of $6.5 \mathrm{mg}$ of WS root extract on Nile tilapia, it was found that this extract with androgenic effects decreased prolactin level and estrogen level by inhibiting aromatase activity and induced male phenotype formation; this phenomenon was proposed to be due to components such as tannin, saponins, terpenoids, steroids, and flavonoids [46].

\section{Discussion}

Traditional and complementary medicine have been more popular nowadays to cure health related conditions [67]. This proposes a new strong potential in traditional and complementary medicine to come up with new medical combinations with fewer side effects [68-70]. Traditional Persian medicine is one of the most well-known categories of traditional medicine using herbal medicine as one of the main therapeutic modalities [71].

Withania somnifera is one of the herbal medicines widely used for the treatment of infertility and sexual dysfunction. This plant has been known to contain more than 80 types of phytochemicals such as steroidal and nonsteroidal alkaloids, steroidal lactones and saponins like isopelletierine, anaferin, anahygrine, hygrine, cuscohygrine, tropine, pseudotropine, withananine, ashwagandha, withaferins, withananinine, pseudowithanine, somnine, somniferine, somniferinine, 3-tropyltigloate, withanine, witha- somine, visamine, mesoanaferine, sitoindoside (7-10), hentriacontane, amino acids such as aspartic acid, glycine, tryptophan, proline, alanine, tyrosine, hydroxyproline valine, cystine, glutamic acid, and cysteine, calcium, phosphorus, iron, flavonoids, starch, reducing sugars, proteolytic enzyme "chamase," glycosides, dulcitol, and volatile oil. Of all these components, withaferin A and sitoindosides had the key role in WS therapeutic effects [11, 13, 23, 33, 34, 60, 61, 72].

Based on the present study, it was shown that extracts of WS fruits, leaves, stems, and especially roots enhance sperm quality indices such as motility and count in men $[12,20,24,25]$ and also decrease the effects of chemical toxins on gonads in both men and women $[13,15,29,33-38,41$, $44,45,59]$. WS can increase gonadal weight in both sexes, enhance folliculogenesis and spermatogenesis, and improve $\mathrm{LH}, \mathrm{FSH}$, and testosterone balances $[15,27,31,35,36,38$, $42,44,45]$. Sexual behavior indices such as female sexual function index and female sexual distress index improve statistically significant after WS extract administration [21].

The mechanism of WS effect on the reproductive system is not known entirely yet, but this mechanism is proposed to be linked to the antioxidative features and ability to improve the hormonal balance of LH, FSH, and testosterone and improve detoxification process. Also, the GABA mimetic feature of WS extract is thought to play the main role in inducing gonadotropin releasing hormone secretion and improving hormonal balance $[23,27,31,34-36,42,44,47,51]$. In the male reproductive system, it is assumed that WS by providing metal ions facilitates enzyme activities, modifies oxidative stress, and prevents cell apoptosis [23]. The root extract of WS has been shown to induce alanine transaminase activity which increases alanine in seminal fluid leading to a less oxidative stress index and improved semen quality [24]. Normalizing lactate, phenylalanine, glutamine, citrate, and histidine in seminal fluid are another feature of WS extract which improves enzymatic processes in tricarboxylic acid cycle (TCA) and fatty acid metabolism $[12,59]$. On the other hand, some animal studies have suggested that WS extract may cause reversible spermicidal and infertilizing effect in male and delayed puberty in both sexes; this might be due to the dose, preparation method, adjuvant components, and duration of use designated in mentioned studies [28, 30, 49, $53,56]$.

\section{Conclusion}

Based on the results, it deems that Withania somnifera has a positive effect in the treatment of infertility both in male and female. Although some studies proposed that WS extract might have infertilizing and spermicidal effect. Due to the growing interest in using herbal medicine especially those which possess the antioxidative and reproductive system supporting properties, further studies are needed to be designed with higher population and more-structured methodology so a more precise and decisive conclusion can be made.

\section{Conflicts of Interest}

The authors declare that they have no conflicts of interest. 


\section{Acknowledgments}

This research was supported by Tabriz University of Medical Sciences and presented as a Ph.D. thesis (Ramin Nasimi Doost Azgomi, no. 3) at School of Traditional Medicine, Tabriz University of Medical Sciences.

\section{References}

[1] R. S. Gibbs, B. Y. Karlyn, A. F. Haney, and I. Nygaard, "Danforth's obstetrics and gynecology: Wolters Kluwer Health Adis (ESP)," 2012.

[2] J. Boivin, L. Bunting, J. A. Collins, and K. G. Nygren, "International estimates of infertility prevalence and treatment-seeking: potential need and demand for infertility medical care," Human Reproduction, vol. 22, no. 6, pp. 1506-1512, 2007.

[3] H. J. Tournaye and B. J. Cohlen, "Management of malefactor infertility," Best Practice \& Research Clinical Obstetrics \& Gynaecology, vol. 26, no. 6, pp. 769-775, 2012.

[4] L. Speroff and M. A. Fritz, Clinical gynecologic endocrinology and infertility: lippincott Williams wilkins, Clinical gynecologic endocrinology and infertility, lippincott Williams \& wilkins, 2005.

[5] J. H. Jung and J. T. Seo, "Empirical medical therapy in idiopathic male infertility: promise or panacea?" Clinical and Experimental Reproductive Medicine, vol. 41, no. 3, pp. 108-114, 2014.

[6] M. Godmann, R. Lambrot, and S. Kimmins, "The dynamic epigenetic program in male germ cells: Its role in spermatogenesis, testis cancer, and its response to the environment," Microscopy Research and Technique, vol. 72, no. 8, pp. 603-619, 2009.

[7] D. R. Smith, E. A. Tanagho, and J. W. McAninch, Smith's general urology, Lange Medical Books/McGraw-Hill, 2008.

[8] C. Krausz, "Male infertility: Pathogenesis and clinical diagnosis," Best Practice \& Research Clinical Endocrinology \& Metabolism, vol. 25, no. 2, pp. 271-285, 2011.

[9] A. Direkvand-Moghadam, Z. Suhrabi, M. Akbari, and A. Direkvand-Moghadam, "Prevalence and predictive factors of sexual dysfunction in Iranian women: Univariate and multivariate logistic regression analyses," Korean Journal of Family Medicine, vol. 37, no. 5, pp. 293-298, 2016.

[10] M. Rafieian-Kopaei, "Medicinal plants and the human needs," Journal of HerbMed Pharmacology, vol. 1, no. 1, pp. 1-2, 2011.

[11] L. Mishra, B. B. Singh, and S. Dagenais, "Scientific basis for the therapeutic use of Withania somnifera (ashwagandha): a review," Alternative Medicine Review, vol. 5, no. 4, pp. 334-346, 2000.

[12] A. A. Mahdi, K. K. Shukla, and M. K. Ahmad, "Withania somnifera improves semen quality in stress-related male fertility," Evidence-Based Complementary and Alternative Medicine, vol. 2011, Article ID 576962, 9 pages, 2011.

[13] V. Sharma, S. Sharma, Pracheta, and R. Paliwal, "Withania somnifera: A rejuvenating ayurvedic medicinal herb for the treatment of various human ailments," International Journal of PharmTech Research, vol. 3, no. 1, pp. 187-192, 2011.

[14] T. K. Biswas and S. Pandit, "In Search of Spermatogenetic and Virility Potential Drugs of Ayurvedic Leads: A Review," Andrology-Open Access, vol. 04, no. 02, 2015.

[15] A. Kumar, R. Kumar, M. S. Rahman, M. A. Iqubal, G. Anand, P. K. Niraj et al., "Phytoremedial effect of Withania somnifera against arsenic-induced testicular toxicity in Charles Foster rats," Avicenna Journal of Phytomedicine, vol. 5, no. 4, p. 355, 2015.
[16] N. J. Dar, A. Hamid, and M. Ahmad, "Pharmacologic overview of Withania somnifera, the Indian Ginseng," Cellular and Molecular Life Sciences, vol. 72, no. 23, pp. 4445-4460, 2015.

[17] G. Singh, P. Sharma, R. Dudhe, and S. Singh, "Biological activities of Withania somnifera," Annals of Biological Research, vol. 1, no. 3, pp. 56-63, 2010.

[18] R. Jain, S. Kachhwaha, and S. Kothari, "Phytochemistry, pharmacology, and biotechnology of Withania somnifera and Withania coagulans: A review," Journal of Medicinal Plants Research, vol. 6, no. 41, pp. 5388-5399, 2012.

[19] A. Saiyed, N. Jahan, S. F. Majeedi, and M. Roqaiya, "Medicinal properties, phytochemistry and pharmacology of Withania somnifera: an important drug of Unani Medicine," Journal of Scientific \& Innovative Research, vol. 5, no. 4, pp. 156-60, 2016.

[20] V. R. Ambiye, D. Langade, S. Dongre, P. Aptikar, M. Kulkarni, and A. Dongre, "Clinical evaluation of the spermatogenic activity of the root extract of Ashwagandha (Withania somnifera) in oligospermic males: a pilot study," Evidence-Based Complementary and Alternative Medicine, vol. 2013, Article ID 571420, 6 pages, 2013.

[21] S. Dongre, D. Langade, and S. Bhattacharyya, "Efficacy and Safety of Ashwagandha (Withania somnifera) Root Extract in Improving Sexual Function in Women: A Pilot Study," BioMed Research International, vol. 2015, Article ID 284154, 2015.

[22] P. Mamidi, K. Gupta, and A. B. Thakar, "Ashwagandha in Psychogenic Erectile dysfunction: Ancillary findings," International Journal of Research in Ayurveda and Pharmacy, vol. 5, no. 1, pp. 36-40, 2014.

[23] K. K. Shukla, A. A. Mahdi, V. Mishra et al., "Withania somnifera improves semen quality by combating oxidative stress and cell death and improving essential metal concentrations," Reproductive BioMedicine Online, vol. 22, no. 5, pp. 421-427, 2011.

[24] A. Gupta, A. A. Mahdi, K. K. Shukla et al., "Efficacy of Withania somnifera on seminal plasma metabolites of infertile males: A proton NMR study at $800 \mathrm{MHz}$," Journal of Ethnopharmacology, vol. 149, no. 1, pp. 208-214, 2013.

[25] M. K. Ahmad, A. A. Mahdi, K. K. Shukla et al., "Withania somnifera improves semen quality by regulating reproductive hormone levels and oxidative stress in seminal plasma of infertile males," Fertility and Sterility, vol. 94, no. 3, pp. 989-996, 2010.

[26] P. Mamidi and A. Thakar, "Efficacy of Ashwagandha (Withania somnifera Dunal. Linn.) in the management of psychogenic erectile dysfunction," AYU (An International Quarterly Journal of Research in Ayurveda), vol. 32, no. 3, p. 322, 2011.

[27] A. A. Al-Qarawi, H. A. Abdel-Rahman, A. A. El-Badry, F. Harraz, N. A. Razig, and E. M. Abdel-Magied, "The effect of extracts of Cynomorium coccineum and Withania somnifera on gonadotrophins and ovarian follicles of immature wistar rats," Phytotherapy Research, vol. 14, no. 4, pp. 288-290, 2000.

[28] P. Mali, P. Chouhan, and R. Chaudhary, "Evaluation of antifertility activity of Withania somnifera in male albino rats," Fertility and Sterility, vol. 90, p. S18, 2008.

[29] N. M. Belal, E. El-Metwally, and I. Salem, "Effect of dietary intake Ashwagandha roots powder on the levels of sex hormones in the diabetic and non-diabetic male rats," World Journal of Dairy \& Food Sciences, vol. 7, no. 2, pp. 160-166, 2012.

[30] I. Ilayperuma, W. D. Ratnasooriya, and T. R. Weerasooriya, "Effect of Withania somnifera root extract on the sexual behaviour of male rats," Asian Journal of Andrology, vol. 4, no. 4, pp. 295-298, 2002. 
[31] E. M. Abdel-Magied, H. A. Abdel-Rahman, and F. M. Harraz, "The effect of aqueous extracts of Cynomorium coccineum and Withania somnifera on testicular development in immature Wistar rats," Journal of Ethnopharmacology, vol. 75, no. 1, pp. $1-4,2001$.

[32] S. A. Dhas, T. Selvaraj, T. Citarasu, S. M. J. Punitha, and M. M. Babu, "Effect of supplemented diet with maturation plant extract on reproductive performance of Etroplus suratansis," Aquaculture Reports, vol. 2, pp. 58-62, 2015.

[33] N. H. Shaikh, V. M. Deshmukh, and M. V. Walvekar, "Alteration in testicular morphology and sperm count due to Glycowithanolides treatment during aging," Asian Journal of Pharmaceutical and Clinical Research, vol. 8, no. 3, pp. 72-77, 2015.

[34] M. Walvekar, N. Shaikh, and P. Sarvalkar, "Effects of glycowithanolides on lipid peroxidation and lipofuscinogenesis in male reproductive organs of mice," Iranian journal of reproductive medicine, vol. 11, no. 9, p. 711, 2013.

[35] R. Kumar, M. Ali, A. Kumar, and V. Gahlot, "Comperative biomedical effect of Withinia Somnifera and Curcuma Longa on ovaries of pesticide induced mice," European journal of pharmaceutical and medical research, vol. 2, no. 7, pp. 249-53, 2015.

[36] R. B. Patil, S. R. Vora, and M. M. Pillai, "Protective effect of spermatogenic activity of Withania Somnifera (Ashwagandha) in galactose stressed mice," Annals of Biological Research, vol. 3, no. 8, pp. 4159-4165, 2012.

[37] R. Rajashree, M. I. Glad Mohesh, M. V. Ravishankar, and P. Sembulingam, "Effect of alcoholic extract of withania somnifera linn roots on reproductive organs in streptozotocin induced diabetic rats," Indian Journal of Public Health Research \& Development, vol. 2, no. 1, pp. 20-23, 2011.

[38] Z. Kiasalari, M. Khalili, and M. Aghaei, "Effect of withania somnifera on levels of sex hormones in the diabetic male rats," Iranian Journal of Reproductive Medicine, vol. 7, no. 4, pp. 163168, 2009.

[39] B. Rahmati, M. H. G. Moghaddam, M. Khalili, E. Enayati, M. Maleki, and S. Rezaeei, "Effect of withania somnifera (L.) dunal on sex hormone and gonadotropin levels in addicted male rats," International Journal of Fertility \& Sterility, vol. 10, no. 2, pp. 239-244, 2016.

[40] P. C. Prabu, K. Biravi, S. Jarisa, S. Sreepriya, and S. Panchapakesan, "Biochemical, pathomorphological and semen characteristics analysis in male wistar rats treated with withania somnifera root extract," Asian Journal of Chemistry, vol. 26, no. 12, pp. 3700-3704, 2014.

[41] D. Bhargavan, B. Deepa, H. Shetty, and A. Krishna, "The protective effect of Withania somnifera against oxidative damage caused by ethanol in the testes of adult male rats," International Journal of Basic \& Clinical Pharmacology, vol. 4, no. 6, pp. 11041108, 2015.

[42] M. Nirupama and H. Yajurvedi, "Efficacy of Ashwagandha (Withania somnifera L.) root extracts in preventing stress induced testicular damage in rat," European Journal of Biomedical AND Pharmaceutical sciences, vol. 2, no. 7, pp. 413-424, 2015.

[43] R. J. K. Kumar, A. Singh, M. Nath, and A. Kumar, "Effect of Withania somnifera on Estrogen, Cholesterol and Subcellular structure of ovary of chlorpyrifos exposed mice," Caribbean journal of science and technology, vol. 1, pp. 1061-1069, 2013.

[44] R. Kumar, M. Ali, J. Singh, A. Nath, and A. Kumar, "Bioremedial impact of Withinia Somnifera on endosulfan exposed spermatozoa of mice," International Journal of Pharmaceutical Sciences and Research, vol. 3, no. 5, p. 1343, 2012.
[45] D. Kaspate, A. Ziyaurrahman, T. Saldanha, P. More, S. Toraskar, and K. Darak, "To study an aphrodisiac activity of hydroalcoholic extract of Withania somnifera dried roots in female Wistar rats," in Proceedings of the International Journal of Pharmaceutical Sciences and Research, vol. 6, p. 2820, 2015.

[46] M. De and S. B. Chakraborty, "Use of Withania somnifera root powder for production of monosex Nile tilapia, Oreochromis niloticus," IOSR Journal of Pharmacy and Biological Sciences, vol. 11, no. 05, pp. 28-31, 2016.

[47] N. D. Jasuja, P. Sharma, and S. C. Joshi, "Ameliorating effect of Withania somnifera on acephate administered male albino rats," African Journal of Pharmacy and Pharmacology, vol. 7, no. 23, pp. 1554-1559, 2013.

[48] S. Saritha, P. S. Reddy, and G. R. Reddy, "Partial recovery of suppressed reproduction by Withania somnifera Dunal. in female rats following perinatal lead exposure," International Journal of Green Pharmacy, vol. 5, no. 2, pp. 121-125, 2011.

[49] L. Garg and G. Parasar, "Effect of Withania somnifera on reproduction in mice," Planta Medica, vol. 13, no. 1, pp. 46-47, 1965.

[50] K. Sahin, C. Orhan, F. Akdemir et al., "Comparative evaluation of the sexual functions and NF-KB and Nrf2 pathways of some aphrodisiac herbal extracts in male rats," BMC Complementary and Alternative Medicine, vol. 16, no. 1, article no. 318, 2016.

[51] N. Shaikh, S. Desai, and M. Walvekar, "Protective effects of glycowithanolides on antioxidative enzymes in testes and accessory reproductive organs of D-galactose induced stressed mice," International Journal of Current Microbiology and Applied Sciences, vol. 3, no. 4, pp. 458-464, 2014.

[52] A. Saiyed, N. Jahan, S. A. Makbul, M. Ansari, H. Bano, and S. H. Habib, "Effect of combination of Withania somnifera Dunal and Tribulus terrestris Linn on letrozole induced polycystic ovarian syndrome in rats," Integrative Medicine Research, vol. 5, no. 4, pp. 293-300, 2016.

[53] P. C. Mali, "Control of fertility in male wistar rats treated with hydroalcholic extract of Withinia somnifera fruits," International Journal of Pharmacology \& Biological Sciences, vol. 7, no. 3, 2013.

[54] J. P. Bhattarai, S. A. Park, and S. K. Han, "The methanolic extract of Withania somnifera acts on $\mathrm{GABA}_{A}$ receptors in gonadotropin releasing hormone (GnRH) neurons in mice," Phytotherapy Research, vol. 24, no. 8, pp. 1147-1150, 2010.

[55] H. Kataria, M. Gupta, S. Lakhman, and G. Kaur, "Withania somnifera aqueous extract facilitates the expression and release of GnRH: In vitro and in vivo study," Neurochemistry International, vol. 89, pp. 111-119, 2015.

[56] A. R. Singh, K. Singh, and P. S. Shekhawat, "Spermicidal activity and antifertility activity of ethanolic extract of Withania somnifera in male albino rats," International Journal of Pharmaceutical Sciences Review and Research, vol. 21, no. 2, pp. 227-232, 2013.

[57] G. Ganu, D. H. Nagore, M. Rangari, and H. Gupta, "Pharmacological evaluation of ayurvedic plants for aphrodisiac activity in experimental animals," Journal of Complementary and Integrative Medicine, vol. 7, no. 1, article no. 31, 2010.

[58] E. Prithiviraj, S. Suresh, N. V. Lakshmi, M. Karthik, L. Ganesh, and S. Prakash, "Protective effect of Withania somnifera (Linn.) on cadmium-induced oxidative injury in rat testis," in Phytopharmacology, vol. 4, pp. 290-90, 269, 2013.

[59] C. N. Kyathanahalli, M. J. Manjunath, and Muralidhara, "Oral supplementation of standardized extract of Withania somnifera 
protects against diabetes-induced testicular oxidative impairments in prepubertal rats," Protoplasma, vol. 251, no. 5, pp. 10211029, 2014.

[60] Q. Uddin, L. Samiulla, V. K. Singh, and S. S. Jamil, "Phytochemical and pharmacological profile of Withania somnifera dunal: A review," Journal of Applied Pharmaceutical Science, vol. 2, no. 1, pp. 170-175, 2012.

[61] S. Imtiyaz, S. J. Ali, M. Aslam, M. Tariq, and S. S. Chaudhary, "Withania somnifera: a potent unani aphrodisiac drug," International Research Journal of Pharmaceutical And Applied Sciences, vol. 3, pp. 59-63, 2013.

[62] I. S. Avicenna, Kitāb al-Qānūn fì al-Tibb (Canon of medicine), Senior Press Superintendent, Jamia Hamdard Printing Press, New Delhi, India, 1998.

[63] A. M. Khan, Eksir-e-Azam (The great elixir), Institute of medicine historical studies, Islamic and complementary medicine, Tehran, Iran, 2007.

[64] M. A. Khorasani, Makhzan al Advieh (The storehouse of medicaments). Research institute for Islamic and Complementary Medicine, vol. 351, Bavardaran Press, Tehran, Iran, 2001.

[65] D. T. Tuhfat al-mu'minin, The Present for the Faithful, Research Center of Traditional Medicine: Nashre Shahr Press, Tehran, Iran, 2007.

[66] S. Inc, SPSS (release 16.0) statistical software, Chicago, Ill, USA, 2008.

[67] P. Fisher and A. Ward, "Complementary medicine in Europe," British Medical Journal, vol. 309, no. 6947, pp. 107-111, 1994.

[68] V. C. Karande, A. Korn, R. Morris et al., "Prospective randomized trial comparing the outcome and cost of in vitro fertilization with that of a traditional treatment algorithm as first-line therapy for couples with infertility," Fertility and Sterility, vol. 71, no. 3, pp. 468-475, 1999.

[69] M. C. Inhorn, Quest for Conception: Gender, Infertility And Egyptian Medical Traditions, University of Pennsylvania Press, 1994.

[70] M. B. Gewali and S. Awale, Aspects of traditional medicine in Nepal, Institute of Natural Medicine University of Toyama, Japan, 2008.

[71] M. J. Abbasi-Shavazi, M. C. Inhorn, H. B. Razeghi-Nasrabad, and G. Toloo, "The 'Iranian ART Revolution': infertility, assisted reproductive technology, and third-party donation in the Islamic Republic of Iran," Journal of Middle East Women's Studies, vol. 4, no. 2, pp. 1-28, 2008.

[72] N. Singh, M. Bhalla, P. de Jager, and M. Gilca, "An overview on Ashwagandha: A Rasayana (Rejuvenator) of Ayurveda," African Journal of Traditional, Complementary and Alternative Medicines, vol. 8, no. 5, pp. 208-213, 2011. 


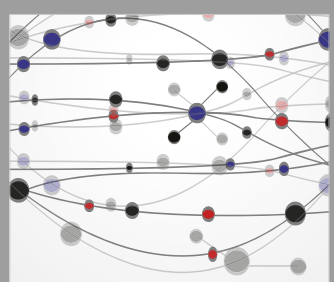

The Scientific World Journal
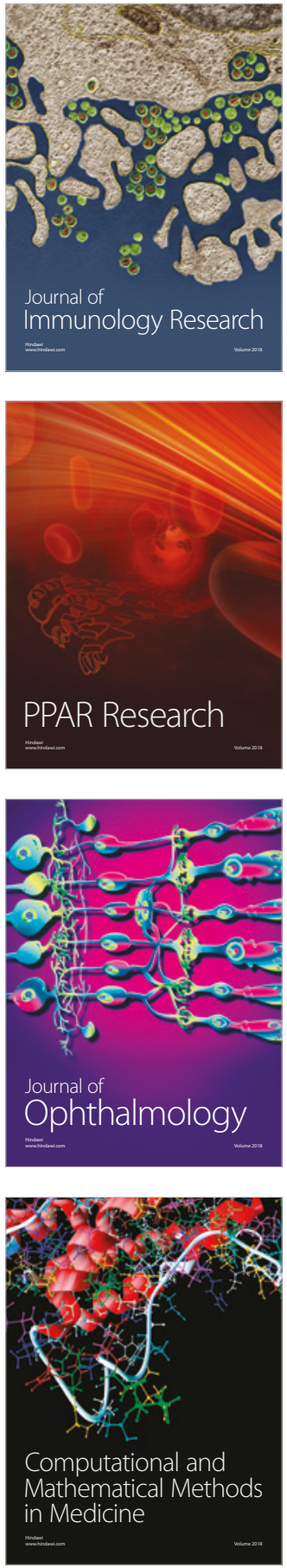

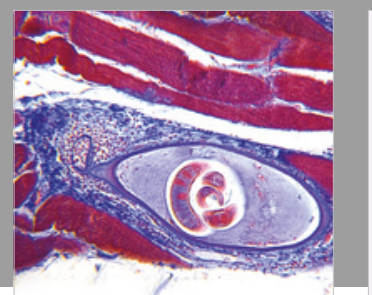

Gastroenterology Research and Practice

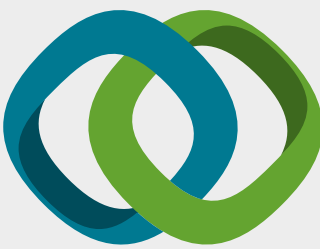

\section{Hindawi}

Submit your manuscripts at

www.hindawi.com
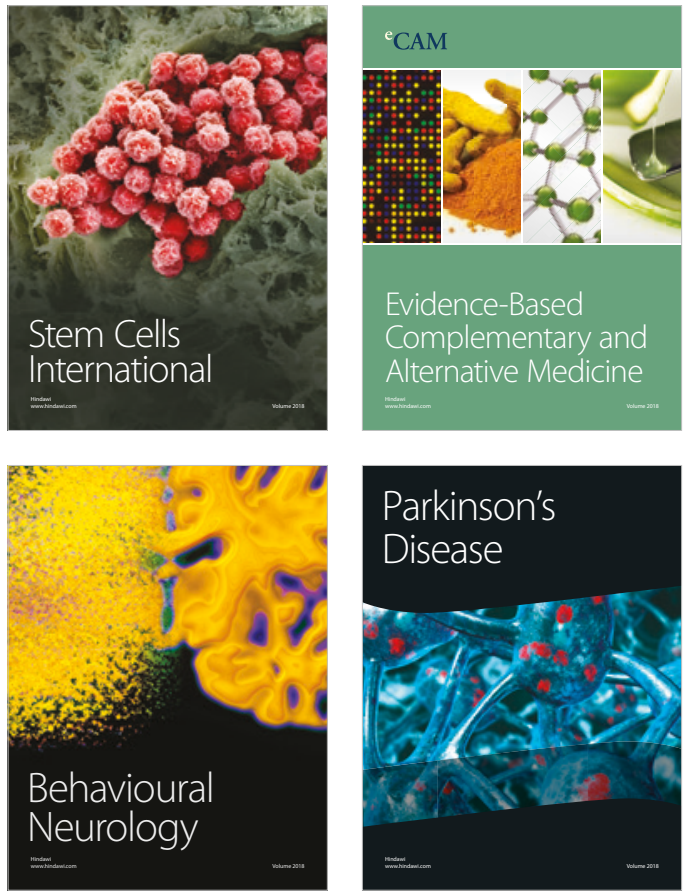

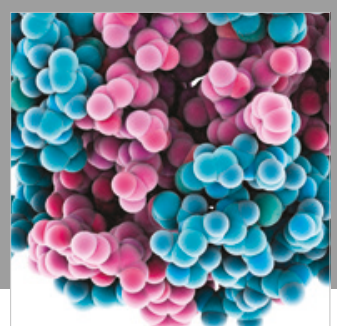

ournal of

Diabetes Research

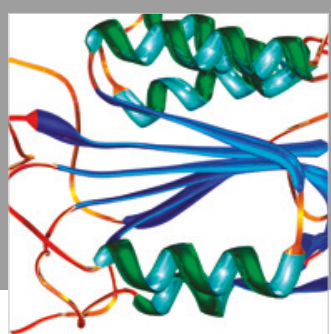

Disease Markers
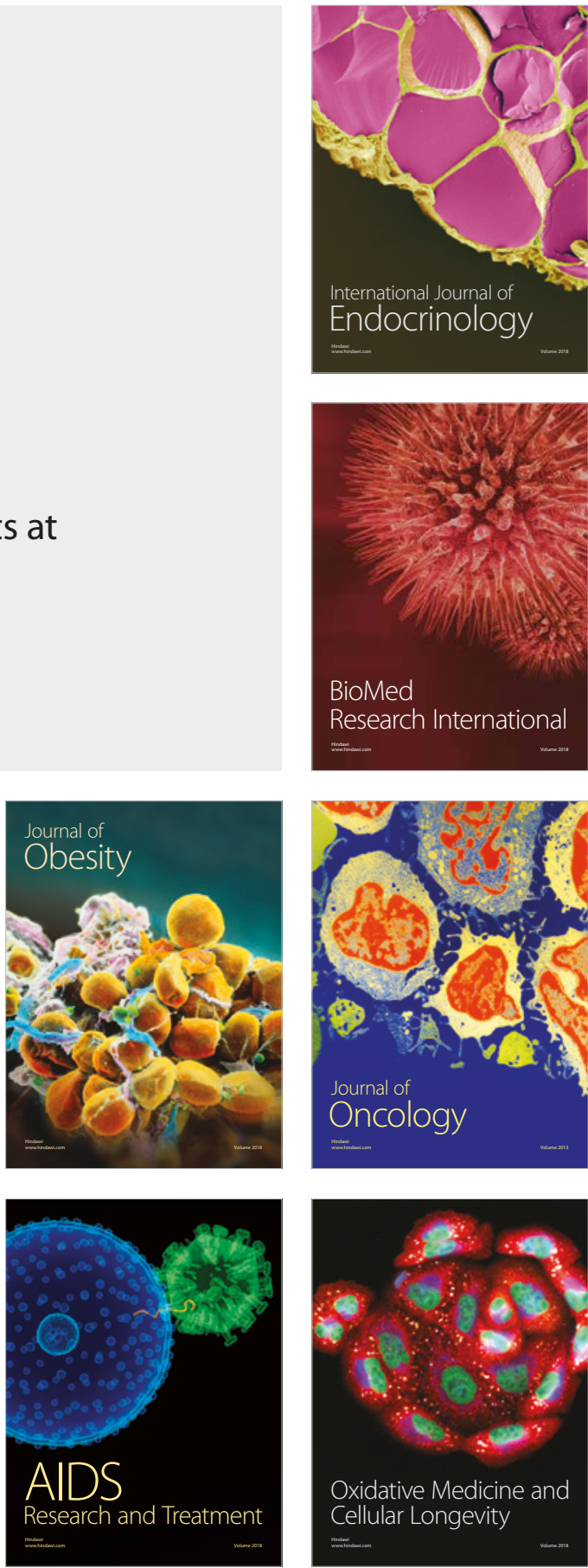